\title{
Measurement of Current with a Pellat-Type Electrodynamometer
}

\author{
R. L. Driscoll
}

\begin{abstract}
The value of an electric current has been determined in absolute measure by means of an electrodynamometer, and simultaneously by standard cells and standard resistors as currently maintained. The electrodynamometer used was of the Pellat type, and featured a fused silica balance beam and single layer helical coils.

The relation of the NBS ampere to the absolute ampere, from this determination, may be expressed as
\end{abstract}

\section{NBS ampere $=1.000013$ absolute amperes.}

The uncertainty in this result from all known sources is estimated to be eight parts per million.

\section{Introduction}

The important units in electrical measurements are the ampere, the ohm, and the volt. Since these units are connected by Ohm's law, any one of the three is fixed when the values of the other two are settled upon. These units are all defined in terms of the mechanical units, but the accuracy of their physical realization depends upon experimental approximations to unattainable ideal conditions. In the electromagnetic system, the ampere is defined as $10^{-1} \mathrm{cgs}$ units, the ohm $10^{9} \mathrm{cgs}$ units and the volt $10^{8} \mathrm{cgs}$ units. The two units so far found susceptible of accurate independent evaluation in terms of the mechanical units are the ohm and ampere. On account of the transitory nature of electric current the ohm and the volt are the two units maintained in the form of concrete standards. It is necessary therefore to assign a value to the standard of electromotive force obtained from a combination of the results of primary standardization of the ohm and ampere. On account of the implicit relation of the electrical units to other physical constants, it is desirable that these units be close to their defined values. In order to detect drifts in the standards, repetition of absolute measurements from time to time has been the accepted practice. Experiments now being conducted at this Bureau on the precession frequency of protons in the magnetic field of a coil carrying a current, show promise of providing a precise method for determining the constancy of the current over long periods of time. An account of the last work on the ampere at this Bureau was published in 1942 [1]. ${ }^{1}$ In that investigation a current balance ${ }^{2}$ was employed; in an effort to avoid possible systematic errors in the current balance, a Pellat-type electrodynamometer [4] (sometimes referred to as a Pellat balance) has been used in this work. In the current balance the force measured is one of translation and in the electrodynamometer it is one of rotation. This paper describes the important physical measurements that were made and assesses the accuracy of the determination of a current by the latter absolute method.

\footnotetext{
Figures in brackets indicate the literature references at the end of this paper. 2 A companion paper to follow in this Journal will present values from recent measurements.
}

\section{Value of a Current in Terms of Mechanical Effects}

The torque between two coils in which the currents $i_{1}$ and $i_{2}$ are held constant has been worked out in a general way by Maxwell [2]. In the particular case of the Pellat electrodynamometer, the two coils are adjusted to be concentric and to have an angle, $\theta$, of $90^{\circ}$ between their axes. With this adjustment the torque, $\mathscr{T}$, is a maximum and is given by

$$
\mathscr{T}=i_{1} i_{2}\left[\frac{\partial M}{\partial \theta}\right]_{\theta=\frac{\pi}{2}}
$$

where $M$ is the mutual inductance of the coils. In absolute measurements the geometrical factor, $\partial M / \partial \theta$, is computed from measured values of the linear dimension of the coils. The mathematical contributions of Snow [3] make possible a second order calculation of this factor for the electrodynamometer that includes several small corrections made necessary by the fact that the coils are helical wires having small measurable irregularities and are not uniform current sheets.

Another factor affecting the absolute measurement of current is the accuracy realized in the evaluation of the torque produced. When single layer helical windings are employed, the torque produced is relatively small and more effort is required for its accurate evaluation than that demanded in the case where multilayer windings are used. The advantage gained in the accuracy of the geometrical factor, $\partial M / \partial \theta$ when single layer helical windings are employed more than offsets the disadvantage of the smaller torque.

\section{Electrodynamometer}

This instrument has a long stationary solenoid (fig. 1) with its axis horizontal; the centered inner coil, mounted on the beam of a balance (fig. 2), is a short solenoid with its axis vertical. The balance beam (fig. 7) is equipped with conventional knife edges and supports the inner coil which thus becomes rotatable about the central knife edge.

With a steady current in both coils in series, the balance is put into equilibrium by means of a suitable 


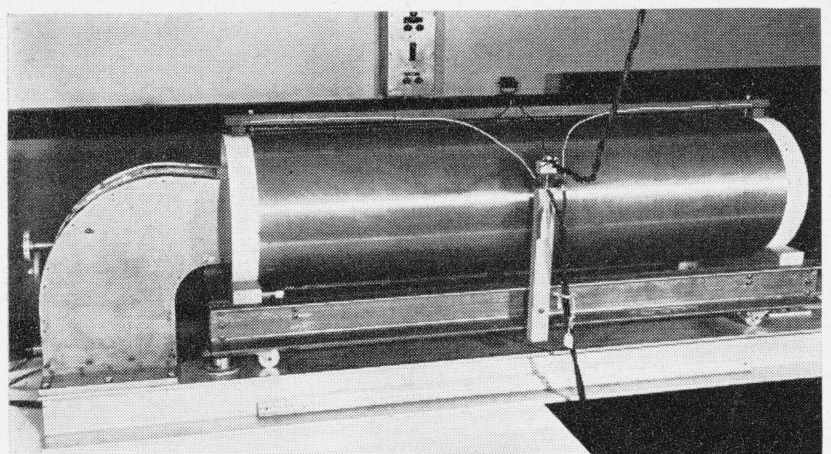

FIGURE 1. Side view of the electrodynamometer.

counterweight; on reversing the current in the stationary coil, the equilibrium of the balance is restored by placing a weight on the arm of the balance. From the known value of the balancing weight, the length of the balance arm, and the geometry of the windings, the value of the current can be calculated by eq 1.

The version of the Pellat electrodynamometer used in this work employs single-layer helical windings of bare wire the dimensions of which can be checked at any time. In his instrument Pellat employed multilayer windings. These windings produced a large torque with permissible currents but the large uncertainty in their linear dimensions would be intolerable according to present requirements. The other important modification in the present instrument is the use of a fused silica balance beam instead of the brass beam of Pellat. The construction of this type of current measuring device was proposed by Harvey L. Curtis as long ago as 1927. Materials for the beam and stationary coil were purchased around 1930. Through the efforts of Roger W. Curtis much of the support for this balance was completed by 1940. At the end of World War II a project was set up for the continuation of the primary standardization of current and it has been pursued without much interruption since 1950. Much encouragement and help on the finishing of the balance beam and the coils was obtained from Charles Moon before his death in 1953

An over-all view of the electrodynamometer with the stationary coil in place is shown in figure 1; in figure 2 the stationary coil has been moved to the side to expose the interior of the instrument. The supports of the balance are mostly of aluminum alloy. A small amount of brass and phosphor bronze was used in the arrestment mechanism. Each piece was tested before finishing to assure that it had low magnetic susceptibility. The agate planes and knife edges of the balance were finished by the Optical Shop of this Bureau, the material for these being donated from the collection of Earl F. Webb. Electrical connections to the rotatable coil are effected by means of two sets of flexible wires. Each set consists of ten 1-mil bare copper wires, in parallel, having a length of about 3 inches. Slack in the wires was adjusted to make their restraint on the balance tolerable.

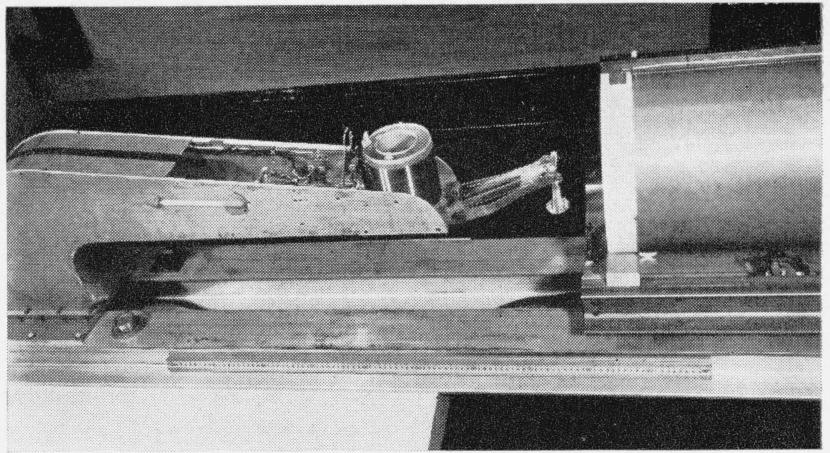

Figure 2. Rotatable coil and balance mechanism.

\section{Construction of the Coils}

Both the stationary and rotatable coils were constructed by the method of Moon that has been described in some detail by Curtis, Moon, and Sparks [5]. Following Moon's method the wire was wound in a helical groove that was produced in the coil form by the process of lapping. The stationary coil form is of fused silica and the rotatable coil form is of Pyrex glass. Oxygen-free copper wire is used in the windings of both coils. Sapphire dies were used to reduce the wire to the desired diameter. After each of the preliminary drawing operations, the wire was spooled on smooth drums in a single layer to avoid kinking. After final drawing, the wire on leaving the die was wound directly in the groove on the coil form.

\section{Measurement of the Dimensions of the Coils}

As far as the stationary coil is concerned, the pitch is the parameter of primary importance, the diameter is of less importance as it appears only in a correction term to take account of the finite length of this coil. On the other hand, the diameter of the rotatable coil is extremely important but the value of its pitch is needed with relatively little accuracy.

\subsection{Pitch Measurement}

The pitch of the rotatable coil was taken as the nominal value of the pitch of the lapped groove which was $2 / 3 \mathrm{~mm}$.

The pitch of the stationary coil was measured by the micrometer method described by Curtis, Moon, and Sparks [5]. Longitudinal readings for the measurement of pitch were taken at several places along the coil in each of six angular positions around the winding. Measurements were made with the coil supported at its ends. It was demonstrated that the bending of the tube when supported in the manner did not affect the measured pitch by as much as 1 ppm. The results are summarized in table 1 .

\subsection{Diameter of Coils}

The importance of the diameter of the rotatable 
coil has already been mentioned. Although the diameter of the stationary coil was not needed with the highest accuracy, considerable pains were taken on account of its potential use as a standard of self inductance, and the values obtained will be recorded here. The method used in measuring both coils was similar to that described by Curtis, Moon, and Sparks [6]. The experimental arrangement of apparatus used in the measurement of the rotatable coil is shown in figure 3 and that used in the case of the stationary coil is given in figure 4 . The results are given in tables 2 and 3 and in figures 5 and 6 . The correction given in table 2 to the diameter of the

TABLE 1. Axial length and pitch of stationary coil

\begin{tabular}{|c|c|c|c|c|c|}
\hline Date, 1952 & $\begin{array}{l}\text { Azimuth } \\
\text { position }\end{array}$ & End std. & $\begin{array}{c}\text { Interval } \\
\text { measured }\end{array}$ & $\begin{array}{l}\text { Intervals } \\
\text { examined }\end{array}$ & $\begin{array}{l}\text { Pitch at } \\
25^{\circ} \mathrm{C}\end{array}$ \\
\hline $\begin{array}{l}21 \text { Mar } \\
24 \text { Mar } \\
25 \text { Mar } \\
25 \text { Mar } \\
26 \text { Mar }\end{array}$ & $\begin{array}{c}\text { Degrees } \\
0 \\
90 \\
180 \\
270 \\
300\end{array}$ & $\begin{array}{c}\text { NBS No. } \\
6,827 \\
6,827 \\
6,827 \\
6,827 \\
6,827\end{array}$ & $\begin{array}{l}\text { Turns } \\
454 \\
454 \\
454 \\
454 \\
454\end{array}$ & $\begin{array}{c}\text { Number } \\
8 \\
8 \\
8 \\
8 \\
8\end{array}$ & $\begin{array}{l}m m / t u r n \\
1.000087 \\
1.000086 \\
1.000085 \\
1.000088 \\
1.000088\end{array}$ \\
\hline $\begin{array}{r}27 \mathrm{Mar} \\
4 \mathrm{Apr} \\
4 \mathrm{Apr} \\
9 \mathrm{Apr} \\
9 \mathrm{Apr} \\
\end{array}$ & $\begin{array}{l}120 \\
300 \\
300 \\
300 \\
120\end{array}$ & $\begin{array}{l}6,827 \\
1,993 \\
1,992 \\
6,827 \\
6,827\end{array}$ & $\begin{array}{l}454 \\
281 \\
274 \\
454 \\
454\end{array}$ & $\begin{array}{l}8 \\
7 \\
6 \\
8 \\
8\end{array}$ & $\begin{array}{l}\text { 1. } 000084 \\
1.000093 \\
1.000090 \\
1.000087 \\
1.000085\end{array}$ \\
\hline \multirow[t]{2}{*}{$\begin{array}{l}10 \mathrm{Apr} \\
10 \mathrm{Apr}\end{array}$} & \multirow[t]{2}{*}{$\begin{array}{r}30 \\
210\end{array}$} & \multirow[t]{2}{*}{$\begin{array}{l}6,827 \\
6,827\end{array}$} & \multirow[t]{2}{*}{$\begin{array}{l}454 \\
454\end{array}$} & $\begin{array}{l}8 \\
8\end{array}$ & $\begin{array}{l}\text { 1. } 000086 \\
\text { 1. } 000087\end{array}$ \\
\hline & & & & \multicolumn{2}{|c|}{ A verage $\ldots 1.000087$} \\
\hline
\end{tabular}

Axial length of coil (1,000 turns) at $25^{\circ} \mathrm{C}$

Axial temperature coefficient of expansion.

$100.0087 \mathrm{~cm}$ $0.2 \mathrm{ppm} /{ }^{\circ} \mathrm{C}$

TABLE 2. Diameter and temperature coefficient of rotatable coil

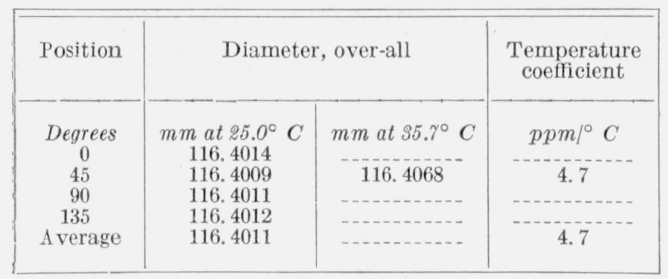

Diameter of wre

\begin{tabular}{|c|c|c|}
\hline \multirow{2}{*}{$\begin{array}{c}\text { Sample } \\
\text { No. }\end{array}$} & \multicolumn{2}{|c|}{ Origin of sample } \\
\cline { 2 - 3 } & $\begin{array}{c}\text { Beginning } \\
\text { of winding }\end{array}$ & $\begin{array}{c}\text { End of } \\
\text { winding }\end{array}$ \\
\hline & & $\begin{array}{c}m m \\
1\end{array}$ \\
2 & 0.5613 & 0.5620 \\
3 & .5619 & .5619 \\
.5617 & .5620 \\
\hline Average & \multicolumn{2}{|c|}{0.5618} \\
\hline
\end{tabular}

A verage over-all diameter at $25.0^{\circ} \mathrm{C}$ -

Wire diameter

Mean diameter of winding, $2 \vec{a}_{2}$, at $25.0^{\circ} \mathrm{C}$

Force on wire during winding

Initial strain in wire, $\mathrm{K}_{2}$

Correction for current distribution, $\frac{\Delta \bar{a}_{2}}{\bar{a}_{2}}$, (see section 7)

Effective radius, $a_{2}=\bar{a}_{2}+\Delta \bar{a}_{2}$

Resistance of winding at $25^{\circ} \mathrm{C}$

Change of resistance with temperature

Thickness of Pyrex glass form

Magnetic susceptibility of form

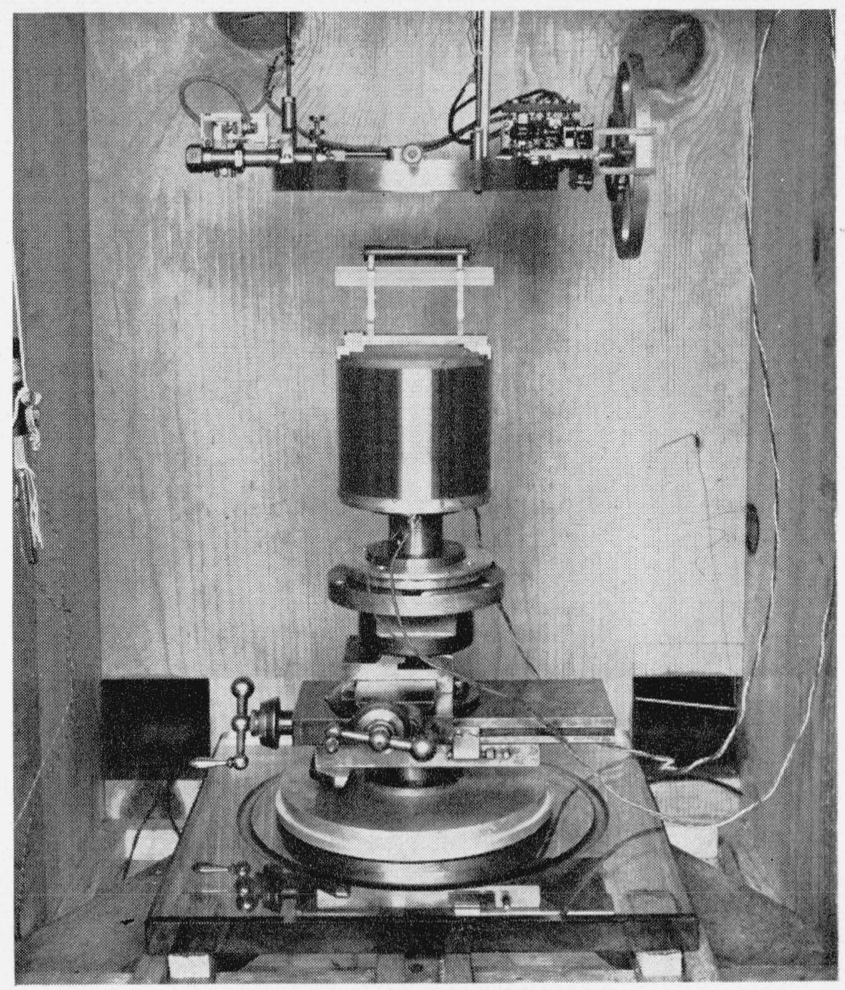

Figure 3. Equipment used in measuring the diameter of the rotatable coil.

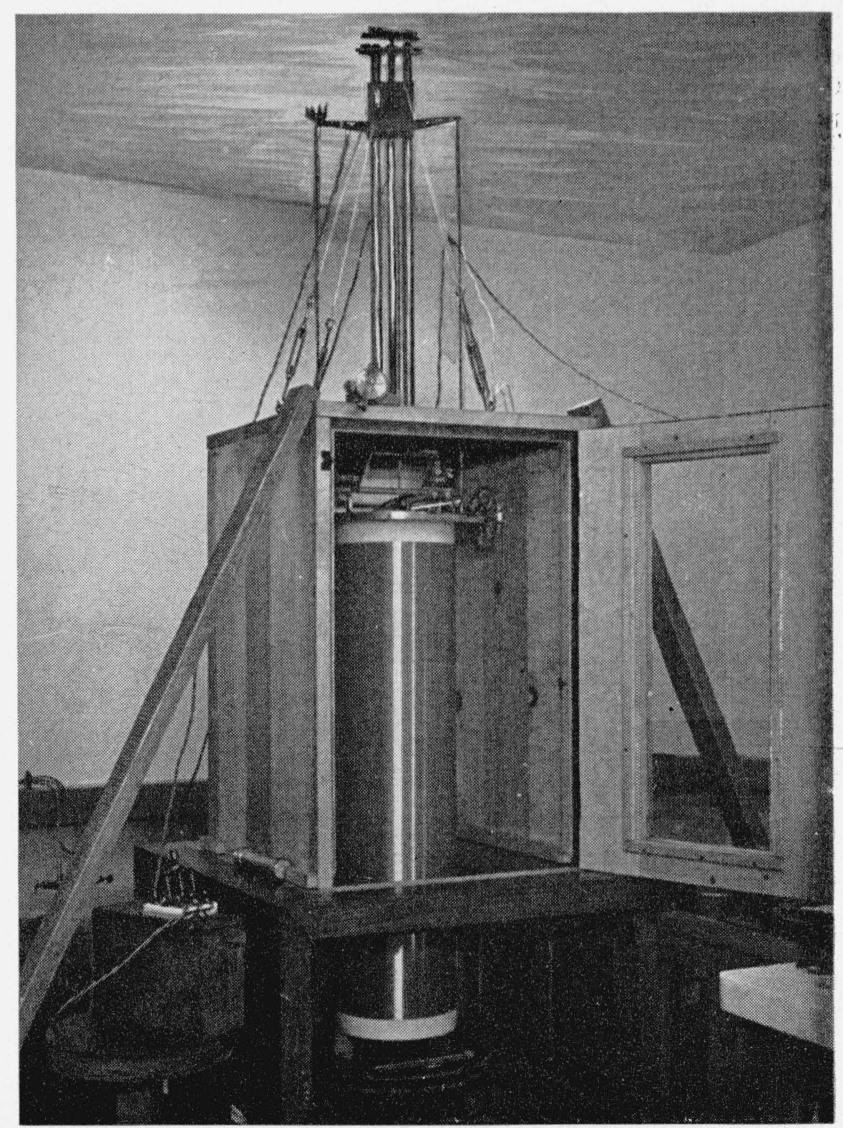

Figure 4. Stationary coil as mounted for the measurement of diameter. 
rotatable coil to take account of the current distribution is based upon the theory of Chester Snow and the experiments of Thomas Wells [7] on the resistivity-strain coefficient of the wire used in this coil as discussed in section 7 .

TABLE 3. Diameter and temperature coefficient of stationary coil

\begin{tabular}{|c|c|c|c|c|c|}
\hline \multirow{2}{*}{ Position } & \multicolumn{4}{|c|}{ Diameter, over-all } & \multirow{2}{*}{$\begin{array}{l}\text { Tempera- } \\
\text { ture coeffi- } \\
\text { cient }\end{array}$} \\
\hline & Top half & $\begin{array}{l}\text { Bottom } \\
\text { half }\end{array}$ & $\begin{array}{l}\text { Bottom } \\
\text { half }\end{array}$ & $\begin{array}{l}\text { Bottom } \\
\text { half }\end{array}$ & \\
\hline Degrees & $m m$ at $25^{\circ} \mathrm{C}$ & mm at $25^{\circ} \mathrm{C}$ & mmat $28.9^{c} C$ & mmat $34.4^{\circ} \mathrm{C}$ & $p p m /{ }^{\circ} C$ \\
\hline 0 & 280.3236 & 280.3235 & - & - & 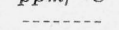 \\
\hline 45 & 280.3243 & 280.3231 & - n..... & - - & $\ldots \ldots$ \\
\hline 90 & 280.3242 & 280. 3246 & & & \\
\hline 135 & 280.3235 & 280.3241 & 280.3253 & 280.3266 & +1.0 \\
\hline A verage & 280.3239 & 280.3238 & - n & .......... & $\ldots$ \\
\hline
\end{tabular}

Diameter of wire

\begin{tabular}{|c|c|c|}
\hline \multirow{2}{*}{$\begin{array}{c}\text { Sample } \\
\text { No. }\end{array}$} & \multicolumn{2}{|c|}{ Origin of sample } \\
\cline { 2 - 3 } & $\begin{array}{c}\text { Beginning } \\
\text { of winding }\end{array}$ & $\begin{array}{c}\text { End of } \\
\text { winding }\end{array}$ \\
\hline & $m m$ & $m m$ \\
1 & 0.6995 & 0.6990 \\
2 & .6992 & .6989 \\
3 & .6992 & .6990 \\
A verage & .6993 & .6990 \\
\hline
\end{tabular}
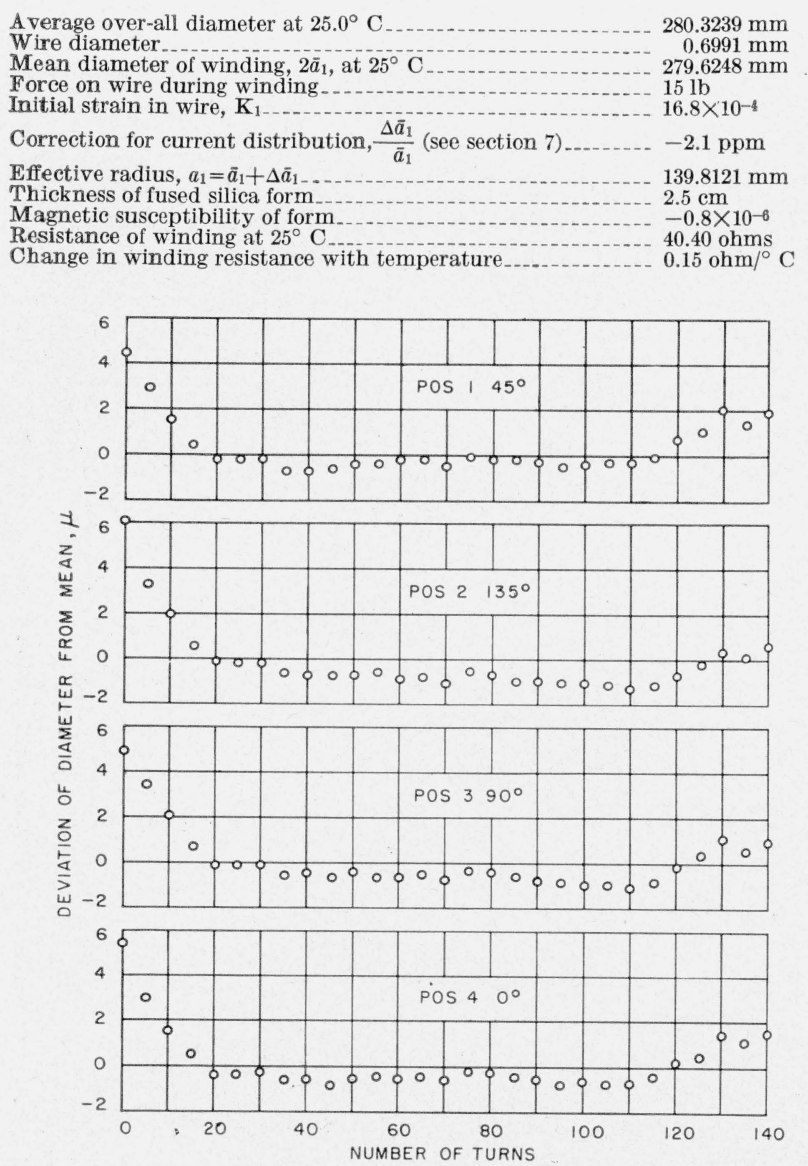

FIGURE 5. Variation in the diameter of the rotatable coil.

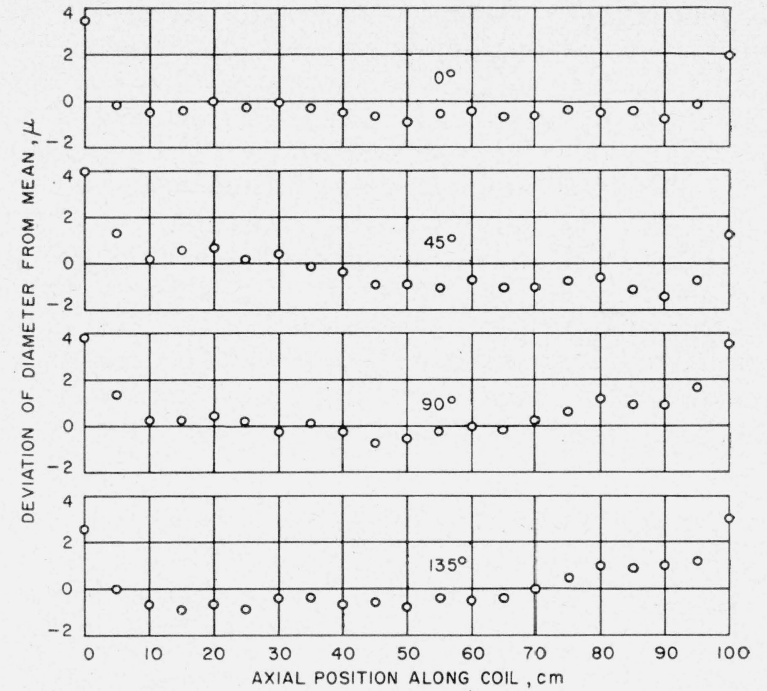

Figure 6. Variation in the diameter of the stationary coil.

\section{Length of the Balance Arm}

The distance between the outer knife edges of the beam, figure 7 , was evaluated by comparison with a calibrated interval on a line standard. The balance beam was mounted on a comparator intended originally for the purpose of comparing line standards. In this instrument the unknown and standard are placed side by side on separately adjustable mountings. These mountings were attached to a carriage that could be moved to bring either the standard or unknown into the field of two rigidly supported microscopes. It was found possible to set the cross hairs of the microscopes over the apexes of the knife edges on the beam in the same manner as on a graduation of a line standard. The difference between the spacing of the outer knife edges and a known interval on the line standard was obtained from the readings of the filar micrometer eyepieces of the microscopes. Through the cooperation of L. V. Judson and B. L. Page of the Metrology Section, facilities were provided for making this measurement.

The ratio of the arm lengths was determined by weighing known masses. As indicated in table 4 no significant difference was found in this ratio over a period of 3 years whether 20 -gram or 3 -gram masses were used. The masses were transposed as far as possible but since the arm lengths differed by 1.5 percent a number of small masses had to be left on one pan. Dividing the unloaded length $\left(l_{1}+l_{2}\right)$ by $\left(1+l_{2} / l_{1}\right)$, where $l_{2} / l_{1}$ is the ratio of the arms when symmetrically loaded, gives a first approximation to the length, $l_{1}$, of the arm chosen to receive the balancing mass. As pointed out by R. D. Cutkosky a further correction must be applied to allow for the increase in the length of the arm when the pan and balancing mass are applied. To measure this distortion, the beam was mounted on a surface plate, the four bosses under the central part of the beam (fig. 7) being secured to the plate with beeswax. 


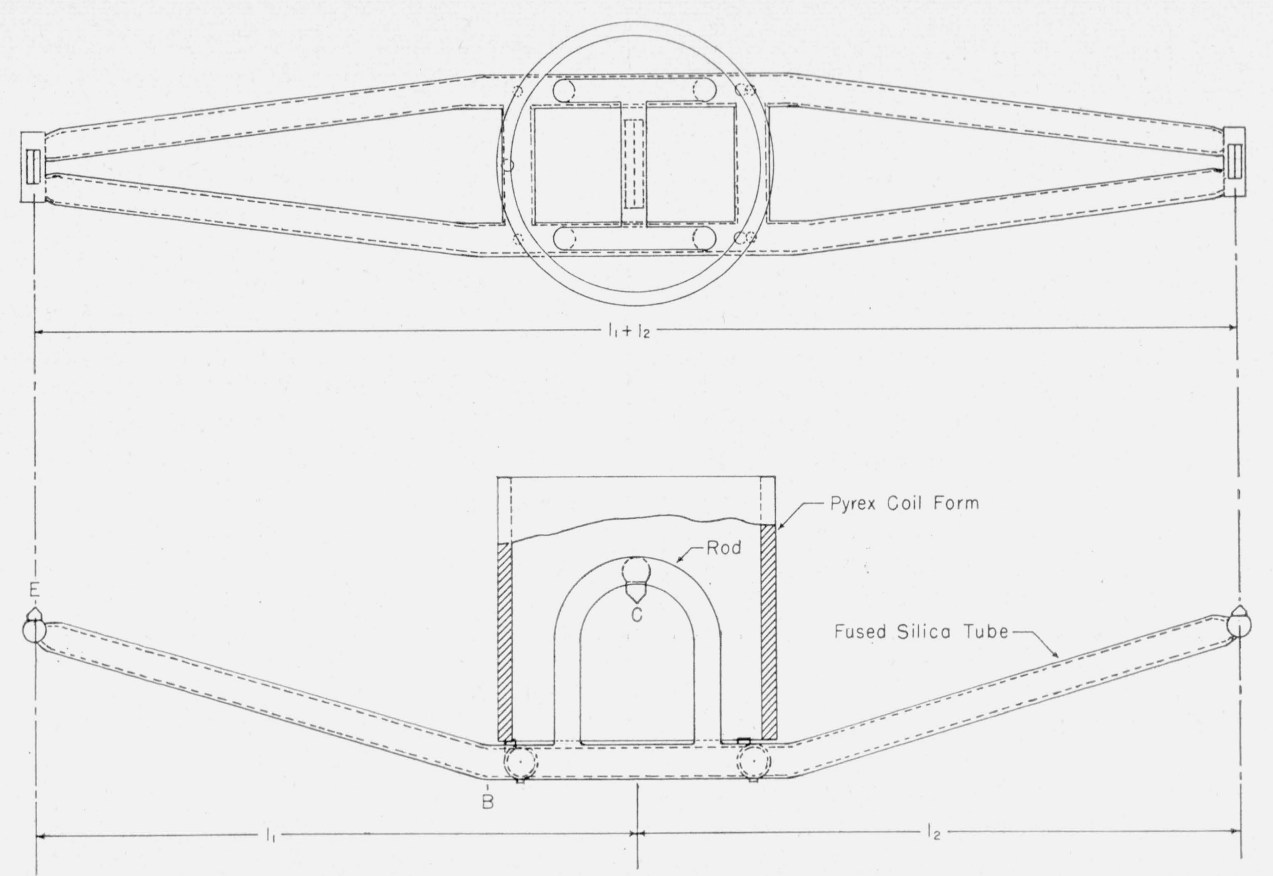

Figure 7. Balance beam and rotatable coil form.

TABLE 4. Length of balance arm

Distance between end knife edges, $\left(l_{1}+l_{2}\right)$

\begin{tabular}{|c|c|c|c|}
\hline \multirow{3}{*}{ Date, 1951 } & \multicolumn{2}{|c|}{ Temperature } & $\begin{array}{c}\left(l_{1}+l_{2}\right) \\
\text { Corr. to } \\
25^{\circ} \mathrm{C}\end{array}$ \\
\cline { 2 - 3 } & Beam & Standard & \\
\hline & ${ }^{\circ} \mathrm{C}$ & ${ }^{C}$ & \\
\hline & & $c m$ \\
28 June & 29.0 & 29.0 & 50.59226 \\
29 June & 27.0 & 27.1 & .59238 \\
29 June & 27.4 & 27.2 & .59234 \\
29 June & 28.0 & 28.1 & .59236 \\
2 July & 26.2 & 26.2 & .59248 \\
6 July & 26.0 & 26.0 & .59251 \\
\hline Average & & & 50.59239 \\
\hline
\end{tabular}

Above values based upon calibrated interval 390 to $896 \mathrm{~mm}$ on meter bar $153-\mathrm{R}$.

Ratio of balance arms, $l_{2} / l_{1}$

\begin{tabular}{|c|c|c|}
\hline Date & $l_{2} h_{1}$ & Condition of weighing \\
\hline $\begin{array}{l}\text { 19-20 Aug. } 1952 \\
\text { 15 Dec. } 1953 \\
\text { 22 July } 1955 \\
\text { 23 July } 1955\end{array}$ & $\begin{array}{r}0.984546 \\
.984548 \\
.984550 \\
.984547\end{array}$ & $\begin{array}{l}\text { 20-gram masses } \\
\text { 3-gram masses transposed } \\
\text { 3-g masses transposed } \\
3-g \text { masses transposed }\end{array}$ \\
\hline Mean.- & 0.984548 & \\
\hline
\end{tabular}

Unloaded length $l_{1}$ of balance arm _.__ $25.49316 \mathrm{~cm}$ Correction (37.1 ppm) for distortion under load $\ldots r$
Effective length at $25^{\circ} \mathrm{C}$
$0.00095 \mathrm{~cm}$

(It was on these bosses that the beam rested during the measurement of the distance between the end knife edges.) By means of a microscope equipped with a filar micrometer eyepiece the endwise movement of the knife edge at E figure 7 was measured when a load equal to the scale pan was applied to that end of the beam. A further complication arises when the standard mass is added to the scale pan and the current in the stationary coil is reversed, that is, there is then an additional increase in the length of the balance arm. Both distortions affect the position of all the load on the end knife edge including, though to a lesser extent, the distributed mass of the balance arm.

In order to discuss these effects, let the following notation be used:

$P=$ Mass of scale pan,

$m=$ standard balancing mass,

$g=$ acceleration of gravity,

$l_{1}=$ unloaded length of balance arm,

$\delta l_{P}=$ change in $l_{1}$ on adding load $P$,

$\delta \mathscr{T}_{P}=$ change in torque to allow for distortion of the distributed mass of beam on adding load $P$,

$\mathscr{T}_{1}=$ torque on rotatable coil with mass $m$ removed and stationary coil current in forward direction,

$\mathscr{T}_{2}=$ torque on rotatable coil with mass $m$ on scale pan and stationary coil current reversed.

If the standard mass $m$ is adjusted so that the balance is in equilibrium for both directions of the stationary coil current, the change in torque on the rotatable coil is given by $\mathscr{T}_{2}-\mathscr{T}_{1}$,

where

$$
\mathscr{T}_{1}=P g\left(l_{1}+\delta l_{P}\right)+\delta \mathscr{T}_{P}
$$

and

$$
\mathscr{T}_{2}=(P+m) g\left(l_{1}+\delta l_{P+m}\right)+\delta \mathscr{T}_{P+m} .
$$

Subtracting the above expressions 


$$
\mathscr{T}_{2}-\mathscr{T}_{1}=m g l_{1}\left[1+\frac{P}{m} \frac{\delta l_{m}}{l_{1}}+\frac{\delta l_{P+m}}{l_{1}}\right]+\delta \mathscr{T}_{m}
$$

The quantity $\delta \mathscr{T}_{m}$ is the change in torque resulting from the additional distortion of the distributed mass of the arm on adding the balancing mass $m$. Its value was estimated from the observed distortion, $\delta l_{m}$, measured at the end knife edge, the dimensions of the various parts, and the density of the material (assumed to be 2.2 for fused silica). Referring to figure 7 it is assumed that the portion of the beam between $\mathrm{C}$ and $\mathrm{B}$ would contribute nothing to $\delta \mathscr{T}_{m}$ on account of the relative stiffness of that part. The part of the arm between B and the cross rod at E is assumed to bend as a cantilever beam fixed at $B$ with concentrated load $m$ at $\mathrm{E}$. The total mass $M_{\tau}$ of the cross rod and knife edge at $\mathrm{E}$ is considered to be concentrated at $\mathrm{E}$. Under these assumptions $\delta \mathscr{T}_{m}$ is given by

$$
\delta \mathscr{T}_{m}=\left[M_{r}+3 / 8 M_{t}\right] \delta l_{m},
$$

where $M_{t}$ is the mass of the arm between $\mathrm{B}$ and the cross rod at E. With this value of $\delta \mathscr{T}_{m}$ eq. (2) becomes

$$
\mathscr{T}_{2}-\mathscr{T}_{1}=m g l_{1}\left[1+\frac{\left(P+M_{r}+3 / 8 M_{t}\right)}{m} \frac{\delta l_{m}}{l_{1}}+\frac{\delta l_{P+m}}{l_{1}}\right] .
$$

Numerical values obtained for the quantities in the brackets of eq $\left(2^{\prime}\right)$ are as follows:

$$
\begin{aligned}
m & =1.481 \text { grams } & M_{t} & =31.5 \mathrm{~g} \\
P & =18.3 \text { grams } & \delta l_{m} / l_{1} & =1.0 \times 10^{-6} \\
M_{\tau} & =4.4 \text { grams } & \delta l_{P+m} / l_{1} & =13.8 \times 10^{-6}
\end{aligned}
$$

When these numerical values are applied in eq $\left(2^{\prime}\right)$ the corrected torque is

$$
\mathscr{T}_{2}-\mathscr{T}_{1}=m g l_{1}\left[1+37.1 \times 10^{-6}\right] .
$$

In effect the unloaded length $l_{1}$ of the balance arm is increased by $37.1 \mathrm{ppm}$ as a result of the distortion under load. The correction for this is applied in table 4 .

\section{Geometrical Factor of the Electro- dynamometer}

The maximum torque, $T$, produced by unit currents in concentric helical wires is given by Snow [3] as follows:

$$
\begin{aligned}
T & =\left[\frac{\partial M}{\partial \theta}\right]_{\theta=\pi / 2} \\
& =4 \pi^{2} \frac{N_{1}}{L_{1}} a_{2}^{2} N_{2} \mu_{1}\left\{1+S+S_{1}+\frac{2}{L_{2} a_{2}} \int_{-L_{2} / 2}^{L_{2} / 2} U_{a}\left(x_{2}\right) d x_{2}\right. \\
& +\frac{a_{1}}{2 \mu_{1}} \int_{-L_{1} / 2}^{L_{1} / 2}\left[\frac{\left(2 x_{1}^{2}-a_{1}^{2}\right)}{\left(x_{1}^{2}+a_{1}^{2}\right)^{5 / 2}} U_{a}\left(x_{1}\right)-\right. \\
& \left.\left.\frac{3 a_{1} x_{1}}{\left(x_{1}^{2}+a_{1}^{2}\right)^{5 / 2}} U_{x}\left(x_{1}\right)\right] d x_{1}\right\}
\end{aligned}
$$

The subscripts 1 and 2 refer to the stationary coil and the rotatable coil respectively, and

$$
\begin{aligned}
a & =\text { radius of coil, } \\
L & =\text { length of winding, } \\
N & =\text { total number of turns in a winding, } \\
x & =\text { axial distance from center of a } \\
& \text { winding, } \\
\mu & =\text { cosine of the angle between the diag- } \\
& \text { onal of a coil and its axis, } \\
U_{x}(x), U_{a}(x)= & \text { observed displacement of any part } \\
& \text { of a winding in an axial or radial } \\
& \text { sense respectively from the posi- } \\
& \text { tion it would have if the winding } \\
& \text { were uniform. }
\end{aligned}
$$

The series $S$ is given by:

$S=\left(1-\mu_{1}^{2}\right) \sum_{n=1}^{\infty}(-1)^{n+1}\left(\frac{r_{2}}{r_{1}}\right)^{2 n} C_{n}\left(\mu_{1}\right) C_{n+1}\left(\mu_{2}\right)\left(n+\frac{1}{2}\right) A_{n}$,

where

$$
\begin{aligned}
A_{n} & =\frac{1 \cdot 3 \cdot 5 \cdots(2 n-1)}{2 \cdot 4 \cdot 6 \cdots \cdot 2 n} \\
C_{n}(\mu) & =\frac{P^{\prime}{ }_{2 n}(\mu)}{n(2 n+1) \mu}, \\
r & =\sqrt{a^{2}+L^{2} / 4}
\end{aligned}
$$

$P_{n}(\mu)$ is Legendre's polynomial of degree $n$, and $P_{n}^{\prime}(\mu)$ is $(d / d \mu) P_{n}(\mu)$.

Also

$$
\begin{aligned}
S_{1}=\frac{\left(1-\mu_{1}^{2}\right)\left(1-\mu_{2}^{2}\right)}{6 a_{2}^{2}} \sum_{n=1}^{\infty}(-1)^{n+l}\left(\frac{r_{2}}{r_{1}}\right)^{2 n} & \\
& \cdot C_{n}\left(\mu_{1}\right) C_{n}\left(\mu_{2}\right) n\left(n+\frac{1}{2}\right) A_{n}\left[n \frac{L_{1}^{2}}{N_{1}^{2}}-\left(n+\frac{1}{2}\right) \frac{L_{2}^{2}}{N_{2}^{2}}\right]
\end{aligned}
$$

The radius of the rotatable coil, $a_{2}$, in eq (3) is the effective radius rather than the mean radius, $\bar{a}_{2}$, of the winding, determined by mechanical measurement. The difference between the effective and mean radii depends on the variation of current density over the cross section of the wire. The "natural" distribution of current density (inversely proportional to distance from the axis of the coil) would certainly apply if the resistivity were constant everywhere in the wire. Some measurements by Wells [7] indicate that for a wire in simple tension, the resistivity-strain coefficient can be represented empirically by

$$
\frac{\Delta \sigma}{\sigma_{0}} / \frac{\Delta l}{l_{0}}=\beta+\gamma\left(\frac{\Delta l}{l}\right)^{2},
$$

where, $\sigma_{0}$, is the resistivity and $l_{0}$ is the length of the unstrained specimen. The constants $\beta$ and $\gamma$ were determined by Wells on oxygen-free copper wire to have the values $\beta=1.13$ and $\gamma=-2.5 \times 10^{4}$. To the extent that the strain at any point in the wire can be 
determined from the initial tension and bending, the resistivity-strain relation can be incorporated in an expression for the current density as a function of the distance from the axis of the coil. A section in the wire cut by a plane through the axis of the coil is shown in figure 8. The coordinates of a point, $P\left(x, y^{\prime}\right)$, are shown as functions of $r$ and $\theta$ in the wire. The current density, $i\left(y^{\prime}\right)$, is assumed to be inversely proportional to $\left(\bar{a}_{2}+y^{\prime}\right)$ and the resistivity, $\sigma\left(y^{\prime}\right)$, and is independent of $x$. The initial strain, $K_{2}$, is known from the winding tension and is taken to be independent of $x$ and $y^{\prime}$. The strain due to bending around the form is assumed to be equal to $y^{\prime} / \bar{a}_{2}$ and independent of $x$. On the basis of these assumptions, the current in a filament of area $r d \theta d r$ is given by

$$
i\left(y^{\prime}\right) r d \theta d r=\frac{C r d \theta d r}{2 \pi\left(\bar{a}_{2}+y^{\prime}\right) \sigma\left(y^{\prime}\right)} .
$$

On setting the strain $\Delta l / l_{0}=\left(K_{2}+\frac{y^{\prime}}{\bar{a}_{2}}\right)$ in eq 4 , the resistivity at any $y^{\prime}$ can be written

$\sigma\left(y^{\prime}\right)=\sigma_{0}\left(1+\beta K_{2}+\right.$

$$
\left.\gamma K_{2}^{3}\right)\left[1+B_{1} \frac{y^{\prime}}{\bar{a}_{2}}+B_{2}\left(\frac{y^{\prime}}{\bar{a}_{2}}\right)^{2}+B_{3}\left(\frac{y^{\prime}}{\bar{a}_{2}}\right)^{3}\right]
$$

where

$$
\begin{aligned}
& B_{1}=\frac{\beta+3 \gamma K_{2}{ }^{2}}{1+\beta K_{2}+\gamma K_{2}{ }^{3}}, \\
& B_{2}=\frac{3 \gamma K_{2}{ }^{2}}{1+\beta K_{2}+\gamma K_{2}{ }^{3}}, \\
& B_{3}=\frac{\gamma}{1+\beta K_{2}+\gamma K_{2}{ }^{3}} .
\end{aligned}
$$

On combining eqs (5) and (6) and neglecting terms of higher order than the third in $\left(y^{\prime} / \bar{a}_{2}\right)$, the current density is given by:

$$
\begin{aligned}
i\left(y^{\prime}\right)=\frac{C}{2 \pi \bar{a}_{2} \sigma_{0}\left(1+\beta K_{2}+\gamma K_{2}^{3}\right)}\left[1-C_{1} y^{\prime} / \bar{a}_{2}+\right. & \\
& \left.C_{2}\left(y^{\prime} / \bar{a}_{2}\right)^{2}-C_{3}\left(y^{\prime} / \bar{a}_{2}\right)^{3}\right],
\end{aligned}
$$

where

$C_{1}=B_{1}+1$,

$\mathrm{C}_{2}=-\left(B_{2}-B_{1}-B_{1}{ }^{2}-1\right)$, and

$C_{3}=\left(B_{3}-B_{2}+B_{1}+B_{1}^{2}+B_{1}^{3}-2 B_{1} B_{2}+1\right)$.

The constant $C / 2 \pi \bar{a}_{2} \sigma_{0}\left(1+\beta K_{2}+\gamma K_{2}^{3}\right)$ must be $i(o)$ and its value, by the integral $\int_{0}^{\rho_{2}} \int_{0}^{2 \pi} i\left(y^{\prime}\right) r d \theta d r$ that

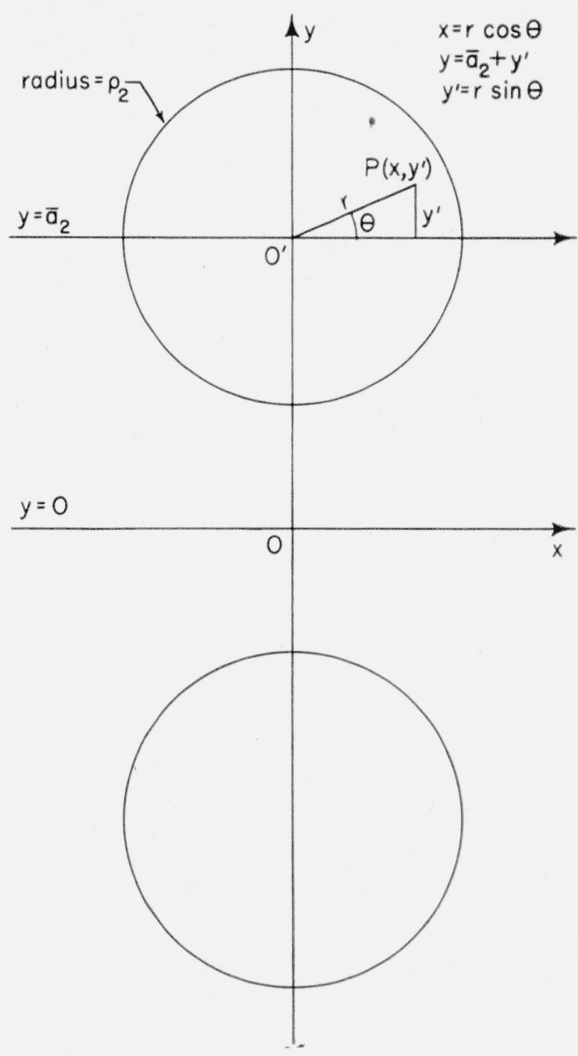

Figure 8. Section through one turn of rotatable coil cut by an axial plane.

makes unit current in the wire is

$$
\frac{1}{\pi \rho_{2}^{2}}\left[1-\frac{C_{2}}{4}\left(\frac{\rho_{2}}{\bar{a}_{2}}\right)^{2}\right] .
$$

If this value be placed in eq 7 one gets

$$
\begin{aligned}
i\left(y^{\prime}\right)= & \frac{1}{\pi \rho_{2}^{2}}\left[1-C_{1}\left(\frac{y^{\prime}}{\bar{a}_{2}}\right)+\right. \\
& \left.C_{2}\left\{\left(\frac{y^{\prime}}{\bar{a}_{2}}\right)^{2}-\frac{1}{4}\left(\frac{\rho_{2}}{\bar{a}_{2}}\right)^{2}\right\}-C_{3}\left(\frac{y^{\prime}}{\bar{a}_{2}}\right)^{3}\right] .
\end{aligned}
$$

The current function, eq (8), is of the same form as that considered by Snow [3] who found that in effect this current distribution in the wire changes its radius from $\bar{a}_{2}$ to $\left(\bar{a}_{2}+\Delta \bar{a}_{2}\right)$ where $\Delta \bar{a}_{2}=\frac{1}{8}\left(\rho_{2}^{2} / \bar{a}_{2}\right)(1-$ $\left.2 C_{1}\right)$, terms in $\left(\rho_{2} / \bar{a}_{2}\right)^{4}$ and higher being neglected. Accordingly one can write to a good approximation, since the constants $\beta, \gamma$, and $K_{2}$ are not known with an accuracy better than a few percent.

$$
\Delta \bar{a}_{2}=-\frac{1}{8} \frac{\rho_{2}^{2}}{\bar{a}_{2}}\left(1+2 \beta+6 \gamma K_{2}^{3}\right)
$$

Likewise it is found that

$$
\Delta \bar{a}_{1}=-\frac{1}{8} \frac{\rho_{1}^{2}}{\bar{a}_{1}}\left(1+2 \beta+6 \gamma K_{1}^{3}\right) .
$$


Numerical values of $\Delta \bar{a}_{2}$ and $\Delta \bar{a}_{1}$ are given in tables 2 and 3.

A summary of the, computations on the constant $T$ is given in table 5 . The following expression, obtained by differentiating the main term of eq (3), was used to take account of small changes in the linear dimensions of the coils:

$$
\frac{\delta T}{T}=2 \frac{\delta a_{2}}{a_{2}}-\frac{4 a_{1}^{2}}{\left(L_{1}^{2}+4 a_{1}^{2}\right)} \frac{\delta a_{1}}{a_{1}}-\frac{L_{1}^{2}}{\left(L_{1}^{2}+4 a_{1}^{2}\right)} \frac{\delta L_{1}}{L_{1}} .
$$

The constant $T$ can be set equal to $F l_{1}$ where $F$ is the force constant referring to the scale pan on balance $\operatorname{arm} l_{1}$. From the results of tables 4 and 5 the value of $F$ is

$$
F=\mathrm{T} / l_{1}=70029.91 \text { dynes } / \overline{\operatorname{cgsu}}^{2} .
$$

The acceleration of gravity $g$ at the scale pan, on the basis of the Dryden reduction [8] and a gravity survey made at this Bureau in 1948 by the Geological Survey, is $980.081 \mathrm{~cm} / \mathrm{sec}^{2}$. The required balancing mass per unit current squared is

$$
F / g=71.45318 \text { grams } / \overline{\operatorname{cgsu}}^{2} .
$$

On reversing the current in the stationary coil the change in torque on the rotatable coil is doubled. After applying a correction to the torque of $-3 \mathrm{ppm}$ on account of the magnetic susceptibility of the coil forms and changing to the practical unit of current, the calculated balancing mass per ampere squared is

$$
2 F\left(1-3.0 \times 10^{-6}\right) / 100 g=1.429059 \mathrm{grams} / \overline{\mathrm{amp}}^{2} .
$$

The correction applied above to the electrodynamometer constant on account of the magnetic susceptibility of the coil forms was estimated in the following manner. From the known susceptibility, $k$, of each coil form, the area $A$ of its cross section, and the mean axial component of field $H_{1}$ existing in the form, the quantity, $q$, of free magnetism existing on its ends was calculated by the expression $q=k A H$.

TABLE 5. Computation of balance constant

\begin{tabular}{|c|c|}
\hline Quantity & Numerical value \\
\hline$\mu_{1-1}$ & $\begin{array}{l}0.963064 \\
.6274\end{array}$ \\
\hline $4 \pi^{2} \frac{N_{1}}{L_{1}} a_{2}^{2} N_{2} \mu_{1}$ & $1.785461 \times 10^{5}$ \\
\hline $\begin{array}{l}C_{1}\left(\mu_{1}\right) \\
C_{2}\left(\mu_{1}\right) \\
C_{2}\left(\mu_{2}\right) \\
C_{5}\left(\mu_{2}\right) \\
S S_{1} \\
S_{1}\end{array}$ & $\begin{array}{l}1.0 \\
0.873111 \\
-.0612 \\
-.212 \\
-63.0 \times 10^{-6} \\
1.0 \times 10^{-8}\end{array}$ \\
\hline 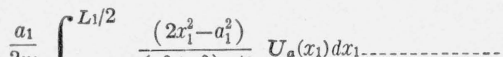 & $+1.0 \times 10^{-6}$ \\
\hline $2 \mu_{1} J_{-L 1 / 2} \overline{\left(x_{1}^{2}+a_{1}^{2}\right) 5 / 2}$ & T1.0人10 \\
\hline$T=[O M \mid O \theta]_{\theta}=\frac{x}{2} \cdots \cdots$ & dyne-cm \\
\hline
\end{tabular}

[Value used for the independent variables:

$a_{1}=13.98121 \mathrm{~cm} . \quad L_{1}=100.0087 \mathrm{~cm} . \quad N_{1}=1000$.

$a_{2}=5.79192 \mathrm{~cm} . \quad L_{2}=9.3333 \mathrm{~cm} . \quad N_{2}=140$.]
The magnetic charge distributed over each end of the stationary coil with one ampere flowing was thus estimated to be $1.5 \times 10^{-3}$ pole. The contribution of the field of these charges to the field at the center of the stationary coil is found to be positive and of the order of one part in $10^{7}$ even if the charges are regarded as point charges on the axis of the coil.

The magnetic charges on the ends of the rotatable coil induced by its own magnetic field are estimated to be 0.56 pole when one ampere is flowing. These charges contribute to the magnetic moment of the coil in the amount of $-5 \times 10^{-3}$ dyne cm/gauss. The magnetic moment of the rotatable coil in the absence of the form is 1,400 dyne $\mathrm{cm} /$ gauss. The correction to the torque on account of the rotatable coil form is thus estimated to be $-3.0 \mathrm{ppm}$. An attempt was made to ascertain experimentally the effect of the aluminum alloy used in the balance support by placing more of this material in the opposite end of the stationary coil. No significant change in the measured torque was observed when approximately twice the original amount of aluminum alloy was added. It must be admitted that it would be difficult by this kind of test to guarantee that the effect was not as large as $1 \mathrm{ppm}$.

\section{Measurement of the Torque}

The electrical connections of the balance are shown in figure 9. During the measurement of the torque, the current was held constant at about $1.02 \mathrm{amp}$ as determined by the standard cell and standard resistor. These standards were maintained at a constant temperature and compared from time to time with this Bureau's primary standards. When the current in the stationary coil was reversed, the change in torque was compensated by placing a mass on the balance arm. The mass (a platinumiridium rod) was adjusted by trial and later evaluated by comparison with known standards. Small corrections to the balancing mass were made from readings on the calibrated scale of the balance. The sensitivity of the balance was $1.8 \mathrm{~cm} / \mathrm{mg}$ and the corresponding half period was about $10 \mathrm{sec}$. The contribution of the current in the leads to the torque was determined separately and subtracted from the total torque. A series of runs, table 6, shows the fluctuations in the experimental result after all known corrections have been applied. The result of each run is derived from ten resting points of the balance each of which is calculated from nine observed turning points. Resting points were obtained at intervals of about $4 \mathrm{~min}$ with the current in the stationary coil alternately in the forward and reversed direction.

\section{Results}

On combining the results of the absolute current measurement with the value of the same current as derived from the NBS electrical standards, the final result of table 7 is obtained. 


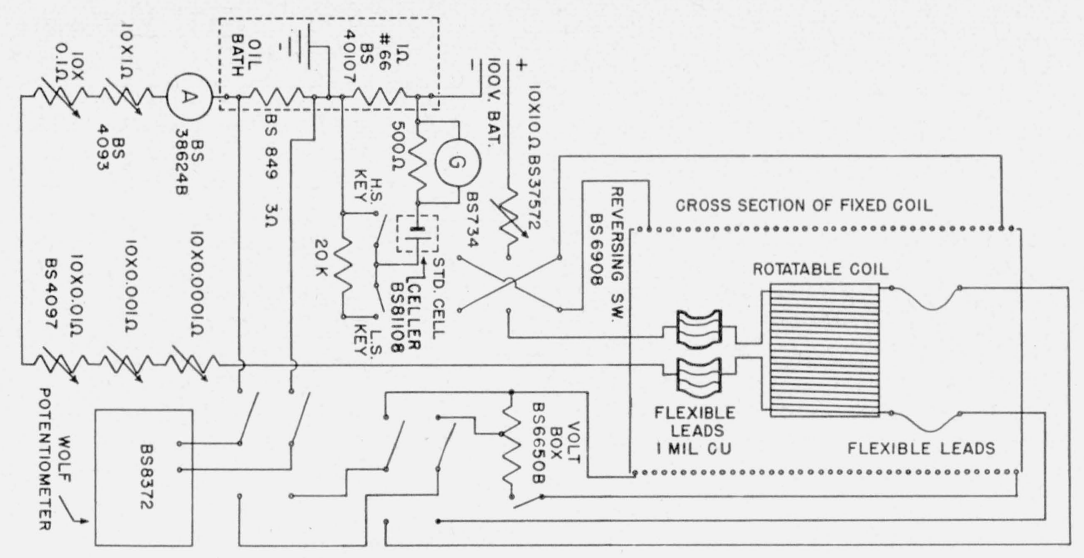

FigurE 9. Electrical connections of the electrodynamometer.

TABLE 6. Determination of balancing mass

[Standard mass (Pt-Ir cylinder) - 1481.146 mg. Buoyaney correction (air density 0.001164 gram/ $/ \mathrm{cm}^{3}$ ) $-0.080 \mathrm{mg}$. Standard mass corrected-1481.066 mg.

\begin{tabular}{|c|c|c|c|c|c|c|c|c|c|}
\hline \multirow{2}{*}{ Date, 1954} & \multirow{2}{*}{\multicolumn{2}{|c|}{$\begin{array}{l}\text { Difference in rest } \\
\text { points of balance }\end{array}$}} & \multicolumn{6}{|c|}{ Corrections to individual trials for departures from $25^{\circ} \mathrm{C}$} & \multirow{2}{*}{$\begin{array}{l}\text { Add to } \\
\text { standard } \\
\text { mass }\end{array}$} \\
\hline & & & \multicolumn{2}{|c|}{ Rot. coil } & \multicolumn{2}{|c|}{ Stat. coil } & \multicolumn{2}{|c|}{ Beam } & \\
\hline $\begin{array}{l}23 \mathrm{Apr} . \\
24 \mathrm{Apr} \\
25 \mathrm{Apr} \\
26 \mathrm{Apr} \\
27 \mathrm{Apr}\end{array}$ & $\begin{array}{l}c m \\
0.002 \\
.012 \\
.011 \\
.016 \\
.013\end{array}$ & $\begin{array}{l}m g \\
0.001 \\
.006 \\
.006 \\
.009 \\
.007\end{array}$ & $\begin{array}{l}\circ C \\
36.9 \\
36.9 \\
36.8 \\
36.7 \\
36.9\end{array}$ & $\begin{array}{c}m g \\
-0.166 \\
-.166 \\
-.164 \\
-.163 \\
-.166\end{array}$ & \begin{tabular}{c|}
$\circ C$ \\
30.8 \\
30.8 \\
30.7 \\
30.6 \\
30.7
\end{tabular} & $\begin{array}{c}m g \\
0.002 \\
.002 \\
.002 \\
.002 \\
.002\end{array}$ & $\begin{array}{c}\circ C \\
29.0 \\
29.0 \\
29.0 \\
29.0 \\
29.0\end{array}$ & $\begin{array}{c}m g \\
0.002 \\
.002 \\
.002 \\
.002 \\
.002\end{array}$ & $\begin{array}{c}m g \\
-0.161 \\
-.156 \\
-.154 \\
-.150 \\
-.155\end{array}$ \\
\hline $\begin{array}{l}28 \mathrm{Apr} \\
28 \mathrm{Apr} \\
29 \mathrm{Apr} \\
30 \mathrm{Apr} \\
1 \mathrm{May}\end{array}$ & $\begin{array}{l}.002 \\
.002 \\
.007 \\
.010 \\
.006\end{array}$ & $\begin{array}{l}.001 \\
.001 \\
.004 \\
.005 \\
.003\end{array}$ & $\begin{array}{l}37.0 \\
37.1 \\
36.7 \\
36.9 \\
37.0\end{array}$ & $\begin{array}{l}-.167 \\
-.168 \\
-.163 \\
-.166 \\
-.167\end{array}$ & \begin{tabular}{l|l}
30.9 & \\
31.0 & \\
30.6 & \\
30.8 & \\
30.9 &
\end{tabular} & $\begin{array}{l}.002 \\
.002 \\
.002 \\
.002 \\
.002\end{array}$ & $\begin{array}{l}29.0 \\
29.0 \\
29.0 \\
29.0 \\
29.0\end{array}$ & $\begin{array}{l}.002 \\
.002 \\
.002 \\
.002 \\
.002\end{array}$ & $\begin{array}{l}-.162 \\
-.163 \\
-.155 \\
-.157 \\
-.160\end{array}$ \\
\hline $\begin{array}{l}2 \text { May } \\
10 \text { May } \\
20 \text { May }\end{array}$ & $\begin{array}{l}.004 \\
.002 \\
.002\end{array}$ & $\begin{array}{l}.002 \\
.001 \\
.001\end{array}$ & $\begin{array}{l}37.3 \\
36.6 \\
36.8\end{array}$ & $\begin{array}{l}-.171 \\
-.161 \\
-.164\end{array}$ & $\begin{array}{l}31.1 \\
30.5 \\
30.7\end{array}$ & $\begin{array}{l}.002 \\
.002 \\
.002\end{array}$ & $\begin{array}{l}29.0 \\
29.0 \\
29.0\end{array}$ & $\begin{array}{l}.002 \\
.002 \\
.002\end{array}$ & $\begin{array}{l}-.165 \\
-.156 \\
-.159\end{array}$ \\
\hline \multicolumn{9}{|c|}{$\begin{array}{l}\text { A verage } \\
\quad \text { Rotatable coil lead effect-1. } \\
\text { Stationary coil lead effect }\end{array}$} & $\begin{array}{c}-0.158 \\
-.111 \\
\text { Negligible }\end{array}$ \\
\hline
\end{tabular}

TABLE 7. Summary of results

\begin{tabular}{|c|}
\hline $\begin{array}{ll}\text { Caleulated balance constant (section 7) } & 1.429059 \text { grams/ampere }{ }^{2} \\
\text { Observed net balancing mass (table 6) } & 1.480797 \text { grams } \\
\text { Current in absolute measure } & 1.017940 \text { amperes } \\
\text { Emf of standard cell NBS } 739 & 1.017935 \text { volts } \\
\text { Resistance of standard resistor No. } 66 & 1.000008 \text { ohms } \\
\text { Current in NBS measure... }\end{array}$ \\
\hline $1 \mathrm{NBS}$ ampere $=1.000013 \pm 0.000008$ absolute amperes \\
\hline
\end{tabular}

Known sources of error affecting the final result in table 7 are enumerated in table 8 . The values given are intended to represent a 50-percent confidence interval in the measured current caused by the estimated uncertainty in the mean values of the quantities listed. The limiting factor in the accuracy of this electrodynamometer at present is the uncertainty in the radius of the rotatable coil. After increasing the radius by a factor of 1.5 and making use of a fused silica coil form it is estimated that the uncertainty in the radius of the rotatable
TABLE 8. Error in the final result

\begin{tabular}{|c|c|}
\hline Quantity & Error \\
\hline $\begin{array}{l}\text { Diameter of rotatable coil } \\
\text { Length of balance arm } \\
\text { Determination of balancing mass } \\
\text { Acceleration of gravity } \\
\text { Pitch of stationary coil } \\
\text { Diameter of stationary coil } \\
\text { Pitch of rotatable coil } \\
\text { Standard resistor No. } \\
\text { Standard cell NBS } 739 \\
\text { Adjustment of coils } \\
\text { Temperature of coils. }\end{array}$ & $\begin{array}{c}p p m \\
6 \\
4 \\
3 \\
3 \\
1 \\
1 \\
1 \\
1 \\
1 \\
1 \\
1\end{array}$ \\
\hline$I_{\mathrm{NBS}} / I_{\mathrm{abs}}$ & 8 \\
\hline
\end{tabular}

coil could ultimately be cut in half. The relatively large uncertainty in the length of the balance arm is not inherent in this method but reflects the need of a more rigid balance beam. 
This undertaking extending over a number of years has accumulated the contributions of many other staff members. In addition to those already named, the author wishes to thank the following: R. D. Cutkosky for valuable support in verifying the results by careful experimental checks; L. P. Slivka for assistance in the design and construction of the balance arrestment mechanism; Catherine Law for the calibration of the standard cell; W. H. Wood for the calibration of the standard resistor; Eleanor Clinton for the calibration of the standard mass; and A. G. Strang for the calibration of the length standards. Helpful suggestions were received from J. L. Thomas and F. B. Silsbee.

\section{References}

[1] R. W. Curtis, R. L. Driscoll, and C. L. Critchfield, J. Research NBS, 28, 133 (1942) RP1449.

[2] J. C. Maxwell, Treatise on Electricity and Magnetism, Clarendon Press, Oxford, Vol. II, Third Ed., Section 583.

[3] Chester Snow, Torque between concentric single layer coils, NBS J. Research 22, 607 (1939) RP1208.

[4] M. H. Pellat, J. Phys. 6, 175 (1887); Bull. Soc. Intern. des Electriciens 2d Series 8, 573 (1908).

[5] H. L. Curtis, Charles Moon, and C. Matilda Sparks, J. Research NBS 21, 375 (1938) RP1137.

[6] H. L. Curtis, Charles Moon, and C. Matilda Sparks, J. Research NBS 16, 1 (1936) RP875.

[7] T. E. Wells. Proc. Instr. Soc. of Am., Vol. II, (1956).

[8] H. L. Dryden, J. Research NBS 29, 303 (1942) RP1502.

Washington, May 13, 1957. 